\title{
Capsule Commentary on Rocha et al., Opinions of Students from a Brazilian Medical School on Online Professionalism
}

\author{
Carol Gonsalves, MD FRCPC MMEd \\ Department of Medicine, The Ottawa Hospital, University of Ottawa, Ottawa, ON, Canada.
}

J Gen Intern Med 29(5):787

DOI: $10.1007 / \mathrm{s} 11606-014-2796-y$

(c) Society of General Internal Medicine 2014

$\mathrm{S}$ ocial media is the communication medium of choice for many. While users of online forums and networking sites may make the distinction between personal and professional posts, posts intended as 'personal' can have negative professional ramifications. Rocha et al. ${ }^{1}$ surveyed 350 Brazilian Medical Students on the frequency with which they had observed ten categorized unprofessional online behaviours. These ranged from $14 \%$ (patient privacy) to $85 \%$ (photos of alcohol consumption). Lapses in patient privacy were universally condemned. Other unprofessional behaviors, such as posing in bathing suits, were judged neutrally.

Some differences in professional expectations as they apply to social media will be influenced by cultural differences, However, given the nature of the physicianpatient relationship and similar codes of ethics for medical professionals in most countries, cultural differences should account for a minority of the variance expected for these standards in the online world. In most countries, professionalism is a central competency in the training of physicians. ${ }^{2,3}$ However, the challenge to educators involved in medical education has been the steadily increased use of social media by students and physicians alike. ${ }^{4}$ Less than $15 \%$ of the Brazilian students in this study report receiving any structured learning in this area. ${ }^{1}$ While the potential consequences of online behaviour may seem intuitive, the fact that these students condemned violation of patient privacy, yet did not find the case vignette depicting the posting of pictures of pediatric patients inappropriate is telling of incongruent judgment in this area. That students judged certain online behaviours more unacceptable from faculty also indicates a potential lack of awareness of the 'permanent' and public nature of the online world and how inappropriate posts may impact a student's career long after they have left the classroom.

Reports from several US medical schools have identified a significant amount of inappropriate online posts by students ${ }^{4}$, with damaging professional consequences. ${ }^{4,5}$ It is our duty to adjust our academic curricula to include online behavior and to evaluate the impact of such programs, so as to avoid harm, embarrassment, and penalties for individual careers, institutions, the medical profession itself and the patients and communities that are served.

Conflict of Interest: The author declares that she does not have a conflict of interest.

Corresponding Author: Carol Gonsalves, MD FRCPC MMEd; Department of Medicine, The Ottawa Hospital, University of Ottawa, Ottawa, ON, Canada (e-mail: cgonsalves@ottawahospital.on.ca).

\section{REFERENCES}

1. Rocha PN and de Castro NAA . Opinions of Students from a Brazilian Medical School on Online Professionalism. J Gen Intern Med. DOI: $10.1007 /$ s11606-013-2748-y

2. Frank JR, Danoff D. The CanMEDS initiative: implementing an outcomes-based framework of physician competencies. Med Teach. 2007;29(7):642-7.

3. Shrank WH, Reed VA, Jernstedt GC. Fostering professionalism in medical education: a call for improved assessment and meaningful incentives. J Gen Intern Med. 2004;19(8):887-92.

4. Thompson LA, Dawson K, Ferdig R, Black EW, Boyer J, Coutts J, Black NP. The intersection of online social networking with medical professionalism. J Gen Intern Med. 2008;23(7):954-7.

5. Chretien KC, Greysen SR, Chretien JP, Kind T. Online Posting of Unprofessional Content by Medical Students. JAMA. 2009;302:1309-15. 